\title{
Proceeding
}

Supplementary Issue: Winter Conferences of Sports Science. Costa Blanca Sports Science Events, 22-23 March 2021. Alicante, Spain.

\section{Core training to reduce the performance gap between abled and disabled athletes in the canoe discipline}

\author{
MANUELE TALEB, SARA ALIBERTI , TIZIANA D'ISANTO \\ University of Salerno, Italy
}

\begin{abstract}
Paracanoe is a sport similar to the Olympic one in terms of rules and equipment, albeit with some differences. The problem concerns the performance gap between able-bodied athletes and the performance of KL3 athletes, attributable to the difficulty in controlling the trunk of the latter due to the weak contact between the lower limbs and the platform. The goal is to verify if, by carrying out core training sessions that aim to improve the stability, power and strength of the trunk in KL3 athletes, it is possible to reduce the performance gap between the two categories of athletes. The champion is made up of 16 athletes who have participated in regional canoe and Paracanoe competitions: champion $A$ is made up of 8 non-disabled male athletes aged 23 to 25 , while champion B is made up of 8 male athletes, between 23 and 25 years, with functional classification KL3. Both groups performed the $200 \mathrm{~m}$ flat-water canoe sprint race before and after 6 weeks, during which time group B performed core-training exercises 3 times a week. The independent sample T test was used as a statistical tool. The result is statistically significant $(p<.05)$ at entry, while after 6 weeks of training, the result is not statistically significant $(p>.05)$. With the use of stabilizing guesswork and core training, it is possible to narrow the gap and encourage sports inclusion.
\end{abstract}

Keywords: Disability; Inclusion; Core training; Gap; Unique competition.

Cite this article as:

Taleb, M., Aliberti, S., \& D'Isanto, T. (2021). Core training to reduce the performance gap between abled and disabled athletes in the canoe discipline. Journal of Human Sport and Exercise, 16(3proc), S1039-S1044. https://doi.org/10.14198/ihse.2021.16.Proc3.21

Corresponding author. University of Salerno, Italy.

E-mail: s.aliberti17@studenti.unisa.it

Abstract submitted to: Winter Conferences of Sports Science. Costa Blanca Sports Science Events, 22-23 March 2021. Alicante, Spain.

JOURNAL OF HUMAN SPORT \& EXERCISE ISSN 1988-5202.

(c) Faculty of Education. University of Alicante.

doi:10.14198/jhse.2021.16.Proc3.21 


\section{INTRODUCTION}

Paracanoe is a sport similar to the Olympic one in terms of rules and equipment, albeit with some precautions. The competitions consist of speed races, which require great strength and power to accelerate and maintain good speed to the finish (Astorino et al., 2016). The means with which propulsion is generated, the paddle, is the same for both disabled and normal-equipped athletes, while the size of the blades and the length of the paddle can change according to the physical characteristics of each athlete. These athletes have characteristics like those of high-level football in terms of performance, particularly for the expression of it and aerobic power, as well as endurance (Izzo et al., 2020; Sannicandro, 2017). Therefore, there are many similarities in the practice of canoeing and kayaking between disabled and able-bodied athletes. Thanks to the improvement of the materials used, techniques and training methods, disabled athletes have been able to achieve ever better performances, getting closer and closer to the performance of non-disabled athletes (Martino et al., 2019; Cascone et al., 2020). Physical exercise and learning are the central question for the disabled people and have to be investigated for every quantitative and qualitative performances (Raiola, 2020ab; Raiola et al., 2018). In this discipline, it is essential to have a stable technique for advanced kayaking skills, especially as regards paddling movements (Hamacher et al., 2018). Flatwater kayak sprint performance can be assessed by analysing the average boat speed a paddler can produce, which has been shown to be directly related to force production levels. The differences between physical and sporting activities for able-bodied and disabled can be seen through the lens of the principle of adaptability (D'lsanto, 2020; 2016). Every physical and sporting activity can be modified or adapted. The problem concerns the performance gap between able-bodied athletes and the performance of KL3 athletes with partial function of the lower limbs, which could be traced back to the difficulty of controlling the trunk of the latter due to the weak contact between the lower limbs and the footrest (Edwards et al., 2019). According to a study, the traction forces on the footrest affect the performance of the kayak (Tornberg et al., 2018). Without a firm foothold, it would not be possible to express strength in the water. The points of support are only raised seat, footrest, and bottom of the canoe (Starczewski \& Molik, 2014). The thrust is transmitted to the hull through the seat and the footrest: each pull of the right arm on the paddle corresponds to a push of the right foot on the footrest, which makes the canoe move forward. Due to the partial limitation of the lower limbs, the KI3 group may find it difficult to maintain contact with the required support points. According to a study, the legs and trunk play a fundamental role in the development of kayaking speed and therefore performance (Brown, 2009). To try to compensate for this lack, we could focus on the core, the kayaker engine, as well as any adaptations of the kayak. The goal is to verify if, by carrying out core training sessions that aim to improve the stability, power and strength of the trunk in KL3 athletes, it is possible to reduce the performance gap between the two categories of athletes and thus allow the holding of a competition.

\section{MATERIALS AND METHODS}

The sample is made up of 16 athletes who have participated in regional canoe and Paracanoe competitions. Sample $A$ is made up of 8 non-disabled male athletes aged 23 to 25 , while sample $B$ is made up of 8 male athletes, between 23 and 25 years, with functional classification KL3. Both groups performed the 200 -meter canoe sprint race in flat water and the time expressed in seconds was taken as a reference parameter. The test was repeated after 6 weeks, a period in which the two groups trained together to encourage inclusion through traditional training and, to try to reduce the performance gap, group B performed additional exercises 3 times a week of core training, to train the stability, strength, and power of the trunk. The materials used to carry out the core training exercises are stick, bosu ball, proprioceptive boards, medicine ball. During the weekly training sessions, and during the tests, the KL3 athletes used stabilizing devices to improve balance 
such as waist straps and leg presser flaps. The independent sample t-test was used as a statistical tool to check the difference between pre and post training groups.

Table 1. Additional core training exercises for KI3.

\begin{tabular}{|c|c|}
\hline \multicolumn{2}{|l|}{ Monday-Exercises to improve core stability: } \\
\hline & Series, Reps and Recovery \\
\hline Plank on board & $3 \times 20 " 30$ break \\
\hline Side plank on board & $3 \times 20 " 30$ break \\
\hline Stability research on fitball and feet on bosu & $3 \times 20 " 30$ break \\
\hline \multicolumn{2}{|l|}{ Tuesday -Exercises to improve core power: } \\
\hline & Series, Reps and Recovery \\
\hline Figure eight with medball & $3 \times 8-1060 / 90$ break \\
\hline Throw diagonally with medball & $3 \times 8-1060 / 90$ break \\
\hline Frontal throws with medball & $3 \times 8-1060 / 90$ break \\
\hline \multicolumn{2}{|l|}{ Thurs day-Exercises to improve core strength: } \\
\hline & Series, Reps and Recovery \\
\hline Cobra on fitball & $3 \times 8-1045$ break \\
\hline Rotations with stick on fitball, feet on bosu & $3 \times 8-1045$ break \\
\hline Speed it up with stick on fitball, feet on bosu & $3 \times 8-1045$ break \\
\hline
\end{tabular}

\section{RESULTS}

Table 2. 200-meter canoe sprint race done prior to the training protocol.

\begin{tabular}{lll}
\hline T-test: two samples assuming different variances & Variable 1 & Variable 2 \\
\hline Average & 45.97325 & 47.53525 \\
Variance & 0.277903071 & 1.47511 \\
Remarks & 8 & 8 \\
Difference assumed for the means & 0 & \\
df & 10 & \\
Stat t & -3.336824913 \\
p (T<=t) one tail & .003765352 \\
$t$ critical one tail & 1.812461123 \\
p (T<=t) two tails & .007530704 & \\
t critical two-tailed & 2.228138852 & \\
\hline
\end{tabular}

Notes: The result shows us that the performance gap between disabled and non-disabled athletes is significant during the $200 \mathrm{~m}$ sprint test canoe in flat water. The result is statistically significant $(p<.05)$ on entry, which indicates a difference in performance between disabled and non-disabled people.

Table 3. 200-meter canoe sprint race performed after the training protocol.

\begin{tabular}{lll}
\hline T-test: two samples assuming different variances & Variable 1 & Variable 2 \\
\hline Average & 43.84825 & 44.41025 \\
Variance & 1.293831643 & 1.076753 \\
Remarks & 8 & 8 \\
Difference assumed for the means & 0 & \\
df & 14 & \\
Stat $t$ & -1.032413249 & \\
$\mathrm{p}(\mathrm{T}<=\mathrm{t})$ one tail & .159692363 & \\
\hline & VOLUME 16 | Proc3 | 2021| S1041
\end{tabular}


t critical one tail

$p(T<=t)$ two tails

t critical two - tailed
1.761310136

.319384726

2.144786688

Notes: The result shows us that the gap between disabled and non-disabled is not statistically significant, so core training has proven effective in reducing the performance difference during the $200 \mathrm{~m}$ sprint test canoe in flat water. After 6 weeks of training, the result is not statistically significant ( $p>.05)$, so the gap has been reduced so that disabled and cannot compete together.

\section{DISCUSSION}

The difference in performance after 6 weeks of training is not significant (Table 3), so the two groups of athletes could compete together. Initially the gap was significant (Table 2) as it was found that the athletes of the $\mathrm{KI} 3$ category, due to limitations, albeit minimal to the lower limbs, possessed poor control of the body, which causes the dispersion of forces due to the weak contact between the lower limbs and footrest. In our case, athletes with lower limb problems do not have a solid foundation on which to push to remain stable. To try to compensate for any lack of balance, at the structural level, customized thigh-presser fins and backrest strap were used, as stabilizing devices are allowed by the regulation, in addition to modifying the construction of the kayak based on the characteristics of the subject, a condition allowed by the FICK regulation. Not all this is enough, in fact, it is also essential to train the kayaker engine that is the core. Many people think that rowing is all in the arms, as champion Nick Troutman argues, however the strokes and movements of the paddle have everything to do with the core. Kayakers use their core muscles to stay upright on the boat to paddle, to paddle keep your back pain free and to remain stable. When the trunk is stable, it is easier and safer to transfer the forces applied along the body to perform any motor task because it improves muscle action and reduces joint loads. Postural control of the trunk is important for stabilizing the whole body (Altavilla et al., 2014; Gaetano et al., 2015) and generating muscle strength during sports. It is important to associate breathing with static and dynamic exercises (Altavilla, 2020). This allows an improvement in terms of posture, efficiency in the movements of daily life or typical of sports actions, contributing fundamentally to the prevention of injuries (D'Elia et al., 2020, Raiola et al.,2020). When a kayaker has greater resistance to injuries, they are able to train harder on the water and handle a higher training load which will result in increased performance. Better core control has not only indirect but also direct impact on performance through better power transfer and maintaining good paddling technique for longer (Magnanini, 2016). Also, not to be forgotten is the inclusive aspect, which was achieved by training disabled and non-disabled people together (Pisapia \& D'Isanto, 2018). Sport has the potential to be an important tool when starting new processes of integration and inclusion (Raiola, 2015ab, Di Palma et al., 2017; Tafuri et al., 2017). Thanks to the training carried out together, athletes with disabilities felt more motivated to improve their condition to try to find equal with their teammates. Training courses for teachers are essential by providing adequate training on teaching methods (D'Elia, 2020) towards inclusive activities. Core training has proven effective in reducing the performance gap between disabled and non-disabled athletes, so that they can compete together to promote sports inclusion. A further solution could also be given by the use of prosthetic limbs, in the case of amputees, since significant differences were found in the performance, strength and use of the footrest (Ellis et al., 2018).

\section{CONCLUSION}

From the study, it emerged that the administration of extra training to athletes in the KL3 category, which deals with core training exercises aimed at greater motor control of the trunk, has favoured the reduction of the performance GAP between non-disabled athletes and KL3 athletes and therefore put in condition the latter to compete with non-disabled athletes. By having the athletes train together, with the use of stabilizing 
conjectures, and by setting up a series of core training workouts exclusively for KL3 athletes, it is possible to reduce the gap and promote sports inclusion.

\section{REFERENCES}

Altavilla, G. (2020). Energetic cost in the different running conditions in team sport for the educational teaching method, Sport Science, 14 (1), pp. 17-20.

Altavilla, G. \& Tafuri, Domenico \& Raiola, Gaetano. (2014). Influence of sports on the control of static balance in physical education at school. Journal of Physical Education and Sport. 14. 351-354. https://doi.org/10.7752/jpes.2014.03053

Astorino, T., Baker, J., Brock, S., Dalleck, L., Goulet, E., Gotshall, R., ... \& Zhou, B. (2016). Dermatoglyphic profile and hand grip strength of the finalists athletes in the Brazilian paracanoe championship. Journal of Exercise Physiology online, 19(1).

Brown, M. B. (2009). Biomechanical analysis of flatwater sprint kayaking (Doctoral dissertation, University of Southampton; University of Chichester).

Cascone, C., De Cesare, G.R., D'Elia, F. (2020). Physical education teacher training for disability, Journal of Human Sport and Exercise, 15, pp. S634-S644. https://doi.org/10.14198//hse.2020.15.Proc3.16

Cataldi, S., Francavilla, V.C., Bonavolontà, V., De Florio, O., Carvutto, R., De Candia, M., Latino, F., Fischetti, F. (2021). Proposal for a fitness program in the school setting during the covid 19 pandemic: Effects of an 8-week crossfit program on psychophysical well-being in healthy adolescents. International Journal of Environmental Research and Public Health, 18 (6), art. no. 3141, pp. 1-12. https://doi.org/10.3390/ijerph18063141

D'Elia, F. (2020). Teachers' perspectives about contents and learning aim of physical education in Italian primary school, Journal of Human Sport and Exercise, 15 (Proc2), pp. S279-S288. https://doi.org/10.14198/ihse.2020.15.Proc2.19

D'Elia, D., Domenico, F.D., Isanto, T.D., Altavilla, G., Raiola, G. (2020) From biomechanics to motor learning, Acta Medica Mediterranea, 36 (5), pp. 3073-3078.

D'Isanto, T., D'Elia, F., Raiola, G., Altavilla, G. (2019) Assessment of sport performance: Theoretical aspects and practical indications. Sport Mont, 17 (1),79-82. https://doi.org/10.26773/smj.190214

D'Isanto, T. (2016). Pedagogical value of the body and physical activity in childhood, Sport Science, 9, pp. 13-18.

D'Isanto, T. (2020). Sports skills in sitting volleyball between disabled and non-disabled people, Journal of Physical Education and Sport, 20 (3), art. no. 194, pp. 1408-1414.

Di Palma, D., Raiola, G., Tafuri, D. (2017). The strategic contribution of sport to the management of diversity, Sport Science, 10 (1), pp. 40-43.

Edwards, J., Bjerkefors, A., Rosen, J., \& Tarassova, O. (2019). Paracanoe. Handbook of Sports Medicine and Science: Canoeing, 106-115. https://doi.org/10.1002/9781119097198.ch9

Ellis, S., Callaway, A., \& Dyer, B. (2018). The influence of lower-limb prostheses technology on Paracanoeing time-trial performance. Disability and Rehabilitation: Assistive Technology, 13(6), 568574. https://doi.org/10.1080/17483107.2017.1357052

Gaetano, R., Lipoma, M., Tafuri, D. (2015). Postural control in young soccer players: Differences between the cognitive approach and ecological-dynamic one Journal of Human Sport and Exercise, 10. https://doi.org/10.14198/ihse.2015.10.Proc1.29

Hamacher, D., Krebs, T., Meyer, G., \& Zech, A. (2018). Does local dynamic stability of kayak paddling technique affect the sports performance? A pilot study. European journal of sport science, 18(4), 491-496. https://doi.org/10.1080/17461391.2018.1435726 
Izzo, R., Raiola, G., D'isanto, T., Cejudo, A., Giovanelli, G.M. (2020). Modelling an adequate profile for a more targeted work methodology, with dedicated technologies, for elite-level footballers: Comparison between sub 17 vs sub 19, highlights and shadows, Sport Science, 13 (1), pp. 36-42.

Magnanini, A. (2016). Inclusive sport possibilities: educational study on Paracanoe. Uluslararası Güncel Eğitim Araştırmaları Dergisi, 2(1), 170-177.

Martino, L., Fonzo, E., Peluso Cassese, F., D'Isanto, T. (2019). Principles of adaptation of the rules for disabled athletes for an inclusion sport. Journal of Human Sport and Exercise. 14. https://doi.org/10.14198/ihse.2019.14.Proc2.08

Pisapia, F., D'Isanto, T. (2018). Inclusive methods of adaptive training in sprints: A theoretical preliminary study, Journal of Physical Education and Sport, 18, art. no. 316, pp. 2101-210.

Raiola, G. (2020a). The Movement and Sport Science in Italy towards the European Research Council, Physical Culture and Sport, Studies and Research, 86 (1), pp. 37-48. https://doi.org/10.2478/pcssr2020-0011

Raiola, G. (2020b). Proposal of rearrangement of physical training and sport sciences methodology academic disciplines in Italian university body. Sport Science, 14 (1): 43-47.

Raiola, G., D'elia, F., Altavilla, G. (2018). Physical activity and sports sciences between European Research Council and academic disciplines in Italy, Journal of Human Sport and Exercise, 13, pp. S283-S295. https://doi.org/10.14198/ihse.2018.13.Proc2.13

Raiola, G., Domenico, F.D., Isanto, T.D., Altavilla, G., Elia, F.D. (2020). Biomechanics core, Acta Medica Mediterranea, 36 (5), pp. 3079-3083.

Raiola, G. (2015a) Inclusion in sport dance and self perception, Sport Science, 8, pp. 99-102.

Raiola, G. (2015b) Sport skills and mental health, Journal of Human Sport and Exercise, 10 (Specialissue), pp. S369-S376. https://doi.org/10.14198/ihse.2015.10.Proc1.27

Raiola, G. (2019) Comparison of exercise and sport sciences epistemology between european research council structure panel and Italian academic system, Sport Science, 12, pp. 112-120.

Raiola, G. (2017)Motor learning and teaching method, Journal of Physical Education and Sport, 17, art. no. 236 , pp. 2239-2243.

Sannicandro, I. (2017). Effects of strength and core stability training versus strength and aerobic training in subjects aged over 65, Medicina dello Sport, 70 (4), pp. 410-418.

Starczewski, M., \& Molik, B. (2014). Selected anaerobic capacity parameters regard to paracanoe functional classification. Postepy Rehabilitacji, 28(1), 31. https://doi.org/10.2478/rehab-2014-0031

Tafuri, D., Di Palma, D., Raiola, G. (2017). The role of the diversity manager for valuing diversity in sport, Sport Science, 10 (1), pp. 70-74.

Tornberg, Å., Håkansson, P., Svensson, I., \& Wollmer, P. (2018). Pulling Forces at the Foot-Rest Influences Power Output Performance on a Kayak-Ergometer. European Journal of Sports \& Exercise Science, 6(3), 112-118.

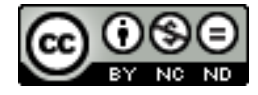

This work is licensed under a Attribution-NonCommercial-NoDerivatives 4.0 International (CC BY-NC-ND 4.0). 